\title{
Leprosy in the Cayman Islands
}

The following report on leprosy in the Cayman Islands by the Medical Officer is of great interest:-

"When did leprosy first make its appearance in the Cayman Islands, and to what extent has its incidence been since the introduction of the malady? Although there are no official records obtainable, from which information could be derived on the matter, I have been fortunate enough to become possessed of valuable data from some of the very aged, whose words can be authentically viewed.

About the year 1825 or thereabout, leprosy first made its appearance in the Cayman Islands in the District of Georgetown, Grand Cayman. The first person to show evidence of the disease was an old woman of African descent (Case 1), whose life was of such a solitary nature, as to render obscure any information about her, beyond the fact that she was a leper. 
About the year 1835 the disease was again discovered in two brothers (Cases 2 and 3), who died in early adult life.

Within a short period following the death of lepers Nos. 2 and 3 the malady was again noticed in a man (Case 4), who as a boy had much to do with leper No. 1, taking food for her and carrying out other orders of friendliness at the instance of his mother.

No other case was heard of until the year 1860 when a man (Case 5), about 28 years of age presented manifestations of the disease. This man from his boyhood days resided at Georgetown, Grand Cayman. As a healthy child about 12 years of age he was partly adopted by Case 4, living in direct association with him, and sharing without restraint an affection most conducive to contagion.

Some years following the discovery that Case 5 had apparently contracted the disease from Case 4 , the next one to show positive evidence of leprosy was a man (Case 6), who was a nephew and neighbour of Case 4. Tradition having handed down the tendency for Caymanians to live gregariously, there was free intermingling between these families, and it may be reasonably assumed that by reason of contact Case 6 contracted the disease from Case 4.

About the year 1877 a mariner (Case 7), residing at Grand Cayman, showed signs of being leprous. This man was a cousin of Case 5, and the two of them growing up together from early life were intimately associated. Becoming suspicious of his condition, he left the island in the year above mentioned, returning in 1910 a pronounced leper, without fingers and feet as evidence of the virulence of his infection. It may not be amiss of me to mention that this man posed in the U.S.A. as a frostbitten sailor, and under this limbless camouflage, peddled books and magazines earning enough money to provide for those days when he became completely disabled.

Approximately about the year 1888 the next in the District to show evidence of the disease was a young man (Case 8). This man was a nephew of Case 5 with whom he had dealings in common. This case was one of a virulent nature ending shortly in death.

In the year 1900 Case 9, residing at Georgetown, was the next to offer convincing evidence that the disease further lurked in the island. It is worthy of mention that this man was the nephew of Case 7 and was raised from infancy in the homestead of his leper uncle who was devoted to him to a degree that would have jeopardized him even under infinitesimal chances of infection through contact.

Soon after the above was discovered the disease next made its appearance in a man (Case 10), who was a cousin of Case 8 and nephew of Case 5. These parties lived in the same compound, helping each other without the slightest pretence at protective measures.

The next in order of sequence to show signs of affliction was Case 11, brother of Case 9 and nephew of Case 7. He lived with his leper uncle under similar conditions as his brother Case 9, hence what has been said with respect to infection through contact involving Case 9, might be applied without exception to Case 11.

In the District of West Bay, Grand Cayman, there are four cases that are distinctly remembered, occurring in two separate families, and there is no vestage of belief that the disease prevailed in that district to a greater extent. In that section the disease manifested itself in the family of a man about 40 years ago. Three in that family, 
father, wife and son, Cases 12, 13 and 14, became lepers and died about 30 years ago.

About the year 1904 that district next furnished a male leper, Case 15, who died of the disease in 1908. From information received from an official source I am convinced that there is no case of leprosy existing in the Lesser Islands, but mention is made that about 40 years ago the death took place of a woman alleged to have been a leper and of whom very little was known.

Of the 15 cases identified over a period of one hundred years, there are two surviving ones, Cases 9 and 10, both over 50 years of age, and afflicted with the anaesthetic form of leprosy. Their presence today is of diagnostic significance as it appears definitely linked with the past, and ensures relative certainty of the exactness of early observations from which we can view a plane of incidence of long standing."

It is of interest that Case 1 apparently infected Case 4, who in turn infected Cases 5 and 6; the former infected Cases 7, 8, 10 and 11 ; Case 7 infected Case 9. With exceptions of Cases 1 and 13, all were males. The special danger of child infection is suggested as in the Case 4 being infected by Case 1 .

The following diagram indicates the spread of infection.

Georgetown

Case $1 q(1825)$

Case $2 \delta$ (1835) Case $3 \delta(1835)$

Case 40

Case 6 Case $5 \delta(1860)$

Case $7 \sigma(1877)$ Case $8 \delta(1888)$ Case $10 \delta$ Case $11 \sigma$

Case $9 \quad \delta$ (1900)

West Bay

Case $12 \delta^{\circ}$ Case $13 q$ Case $14 \sigma^{\circ}$

Case 15 ठ (1904)

(Dotted lines show course of infection). 